\begin{tabular}{|c|c|c|}
\hline PORT SAID ENGINEERING RESEARCH JOURNAL \\
Faculty of Engineering - Port Said University \\
Volume (21) No. (2) September 2017 pp. 68:77
\end{tabular}

\title{
Durability Improvement of Self Compacting Recycled Aggregate Concrete Using Marble Powder
}

\author{
Kamal G.Sharobim ${ }^{1}$, Hassan M.Hassan ${ }^{2}$ and Shady R.Ragheb ${ }^{3}$
}

\begin{abstract}
Marble powder is available in various parts of the world abundantly as there is a great demand of marble stones. The particle size of this material is marginally courser compared to cement and fly ash. In the present study, results of an experimental study to show the possibility of use of marble powder in self-compacting concrete (SCC), it clearly shows that Marble powder can be used in SCC. Different SCC mixes were produced with cement contents of $450 \mathrm{~kg} / \mathrm{m}^{3}, 50 \%$ RCA replacement and 3\% admixture while the used filler material was $0 \%, 10 \%, 20 \%, 30 \%$ and $40 \%$. The effect of MP on key fresh properties such as filling ability, passing ability and segregation resistance of SCC were investigated and the effects on RCA hardened concrete such as compressive and indirect splitting strengths, abrasion resistance, Cantabro test and RCPT test to improve durability. The test result revealed that the filling ability, passing ability and segregation resistance of SCC were improved for 30\% and 40\% MP. The test result of hardened concrete revealed that mixes up to $20 \%$ MP give normal strength and mix with 10\% MP improves durability. The overall test results suggest that using $10 \%$ MP as partial replacement of cement produce SCC without affecting the key fresh properties of concrete and improved durability.
\end{abstract}

Keywords: filling ability, passing ability, recycled concrete aggregate, segregation resistance, self-compacting concrete

\section{INTRODUCTION}

Self-compaction is often described as the ability of the fresh concrete to flow under its own weight over a long distance without segregation and without the need to use vibrators to achieve proper compaction. This saves time, reduces overall cost, improves working environment and opens the way for the automation of the concrete construction [1-4].

Self-Compacting Concrete (SCC) mixes always contain a powerful super plasticizer and often use a large quantity of powder materials and/or viscosity-modifying admixtures. The super plasticizer is necessary for producing a highly fluid concrete mix, while the powder materials or viscosity agents are required to maintain sufficient stability/cohesion of the mixture, hence reducing bleeding, segregation and settlement [4]. Benefits of using SCC also include: improving homogeneity of concrete production and the excellent surface quality without blowholes [5].

Recycled aggregate has been used as a replacement of the natural aggregate. Many studies have shown that using recycled aggregate in concrete suffers from durability problems. Cui et al.'s [6] reported that the carbonation

\footnotetext{
${ }^{1}$ professor, Faculty of Engineering, Suez Canal University, Egypt, Email: ksharobim@yahoo.com

${ }^{2}$ professor, Faculty of Engineering, Port Said University, Egypt, Email: Hassanibrahim@yahoo.com

${ }^{3}$ Assistant lecturer, Faculty of Engineering, Port Said University, Egypt, Email: Shadyragheb@hotmail.com
}

level of recycled aggregate concrete was 3 times that of natural aggregate concrete.

Crentsil et al.'s [7] and Levy Salmon and Helene's [8] experimental result showed that after 6 months of curing the carbonation depth of recycled aggregate concrete was $1.3-2.5$ times than that of the reference one. Otsuki et al. [9] reported that the resistance of recycled aggregate concrete to chloride ion penetration and carbonation were slightly inferior to those of natural aggregate concrete given the same water-binder ratio was used .

Disposal of the waste materials of the marble industry, consisting of very fine powders, is one of the environmental problems worldwide today. However, these waste materials can be successfully and economically utilized to improve some properties of fresh and hardened self-Compacting Concrete (SCC) [10]. Valeria Corinaldesi et al. [11] stated that due to its quite high fineness, marble powder proved to be very effective in assuring very good cohesiveness of mortar and concrete. It is used for other ultrafine mineral additions (such as silica fume) that are able to confer high cohesiveness to the concrete mixture. Moreover, an even more positive effect of marble powder is evident at early ages, due to its filler ability. The use of fillers is intended to enhance the particle distribution of the powder skeleton, reducing inter particle friction and ensuring greater packing density. This can promote release of a portion of the mixing water that would otherwise be entrapped in the system [12]. 
Thus, successful utilization of Marble Powder (MP) in SCC could turn these materials into a precious resource. Moreover, these mineral admixtures can significantly improve the workability of self-compacting $[13,14]$. When used in SCC, these mineral admixtures can reduce the amount of super plasticizer necessary to achieve a given property [15]. It should be noted that the effect of mineral admixtures on admixture requirements is significantly dependent on their particle size distribution as well as particle shape and surface characteristics. From this viewpoint, a cost effective SCC design can be obtained by incorporating reasonable amounts of MP [16]. The addition of MP is the best mineral admixture among LP, BP and MP, to improve the properties of fresh SCC such as slump-flow, T50 time, L-box ratio, and segregation resistance.

A lot of researches were performed to study the effects of filler materials on the properties of SCC. These studies showed that the use of filler materials improves workability with reduced cement content. By this way, low heat of hydration and decreased thermal and shrinkage cracking can be achieved $[17,18]$. Belaidi et al. stated that at a constant water/binder ratio and super plasticizer content, the use of natural pozzolana and marble powder by substitution to cement has no negative effects on the workability of SCC [19]. Industrial by-products such as fly ash (FA), stone dust, silica fume and blast furnace slag are generally used as filler materials in SCC [13,20]. This helps to provide economic benefits and reduce environmental pollution [21]. The SCC mixtures were assessed as "low" chloride permeability concretes as per ASTM C 1202-94 assessment criteria, with less than 2000 coulombs of total charge passing, so the durability of SCC enhances due to the decrease in permeability [14,22]. Ho et al. [3] demonstrated that the granite fines, as supplied, could be used successfully in the production of SCC. The marble has been commonly used as a building material since ancient times.

The negative effect of recycled aggregate on concrete quality limits the use of this material in structure concrete. However, it has been suggested that the short comings of using recycled aggregate can be mitigated by using the double mixing approach in concrete mixing, particularly for concrete prepared with high water-binder ratio as it has been demonstrated that improvements in strength. Chloride penetration and carbonation resistance of recycled aggregate concrete can be achieved.

It has also been shown that by the negative effect of RCA can be mitigated by incorporating a certain amount mineral admixtures $[23,24]$. Recently Kou et al. [25, 26] found that Class F fly ash was used as an additional or cement replacement in the RCA mixes, it can improve the mechanical and durability properties of recycled aggregate concrete.

In the present study, the MP derived from tested concrete was used to produce SCC substituting 0-40\%. The effects of MP on the key properties of fresh SCC such as filling ability, passing ability, and segregation resistance of SCC were observed; also this paper presents the result of a study on the use of marble powder as a substitution and addition of cement in recycled aggregate concrete to improve the durability properties of the concrete.

\section{MATERIALS AND METHODS 2.1. Materials}

Two types of aggregates are used; crush dolomite and recycled concrete aggregate. The used fine aggregate is natural sand. The nominal size of both coarse aggregates is $20 \mathrm{~mm}$. The physical properties of recycle concrete aggregate (RCA), natural coarse aggregate (NCA) and fine aggregate (FA) are shown in Table1.

Table 1: Basic physical properties of fine and coarse aggregate.

\begin{tabular}{|c|c|c|c|c|}
\hline $\begin{array}{c}\text { Physical } \\
\text { properties }\end{array}$ & RCA & NCA & FA & $\begin{array}{c}\text { Limits of } \\
\text { ESS1109 }\end{array}$ \\
\hline Specific gravity & 2.6 & 2.64 & 2.65 & $2.5 \longrightarrow 2.75$ \\
\hline $\begin{array}{c}\text { Unit } \\
\text { weight(gm./cm }\end{array}$ & 1.65 & 1.7 & 1.55 & ------ \\
\hline $\begin{array}{c}\text { Absorption } \\
\text { percent }\end{array}$ & 1.9 & 1.7 & 1.3 & $\begin{array}{c}\text { Not exceed } \\
2.5 \%\end{array}$ \\
\hline
\end{tabular}

The size distributions of FA, NCA, and RCA were within the ESS1109 limits, as shown in Figures 1\&2. RCA had porous surfaces consisting of reclaimed mortar and thus possessed a higher absorption value than NCA (Table $1)$.

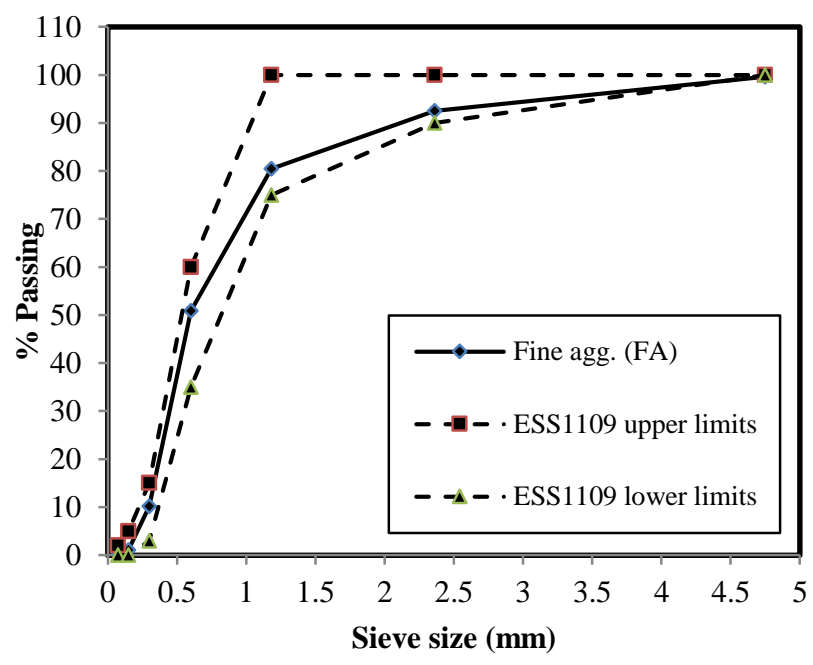

Figure 1: Grading curve of fine aggregate and ESS1109 limits. 


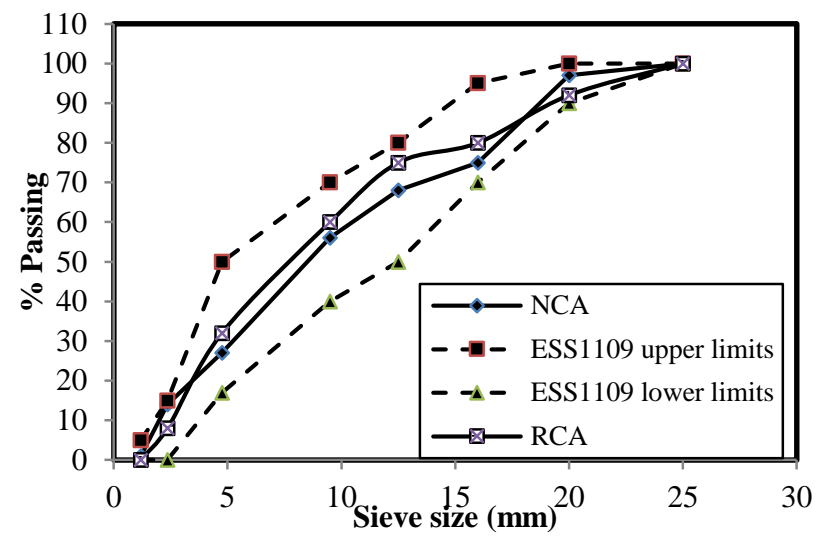

Figure 2: Grading curve of coarse aggregate and ESS1109 limits.

The aggregates were bond together by means of paste, which contained cement and water. ASTM Type I Portland cement (C) was used as the binder. The mix water (W) used was normal tap water. Also, marble powder (MP) was used as filling material and 3\% additives (Sikament-NN) was used to obtain the required fresh properties of SCC without segregation. The specific gravity of cement was 3.12 and for marble powder was 2.42 .

\subsection{Concrete Mix Properties}

Five mixes are used one of them without MP and the five different mixes were produced with MP substituting $10 \%, 20 \%, 30 \%$ and $40 \%$. The basic mix proportions of these concretes were calculated based on the absolute volume of constituent materials. All mixes contain 3\% additives and $50 \%$ RCA. The mix proportions of control and MP concretes are shown in Table 2.

Table 2: Mix proportions of SCC mixes (volume of concrete: $1 \mathrm{~m}^{3}$ ).

\begin{tabular}{|c|c|c|c|c|c|c|c|c|}
\hline$\stackrel{凶}{\Sigma}$ & $\cup$ 영 & 38 & 至 & 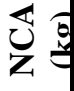 & $\bigcup_{\mathscr{A}}^{\mathbb{E}}$ & 区 & $<$ & $\overbrace{2}^{2}$ \\
\hline $\begin{array}{l}\mathbf{0 \%} \\
\text { MP } \\
\end{array}$ & $\stackrel{゚}{\Upsilon}$ & $\stackrel{0}{\Sigma}$ & 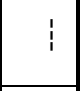 & రె & $\bar{b}$ & $\frac{\infty}{\infty}$ & 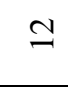 & $\stackrel{\Upsilon}{ }$ \\
\hline $\begin{array}{c}10 \% \\
\mathrm{MP}\end{array}$ & @̊ & $\infty$ & $\stackrel{\curvearrowleft}{\forall}$ & $\bar{b}$ & $\bar{b}$ & $\stackrel{\infty}{\infty}$ & 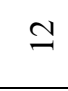 & $\stackrel{\Upsilon}{~}$ \\
\hline $\begin{array}{r}20 \% \\
\mathrm{MP}\end{array}$ & : & $\infty$ & ๙ & $\bar{b}$ & $\bar{b}$ & $\underset{\infty}{\infty}$ & 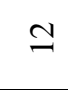 & $\stackrel{\Upsilon}{\text { I }}$ \\
\hline $\begin{array}{c}30 \% \\
\text { MP }\end{array}$ & $\frac{n}{n}$ & $\bar{a}$ & $\stackrel{n}{n}$ & $\bar{n}$ & $\bar{n}$ & $\stackrel{n}{\infty}$ & 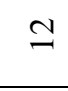 & $\stackrel{\Upsilon}{~}$ \\
\hline $\begin{array}{c}40 \% \\
\text { MP }\end{array}$ & $\stackrel{ }{\curvearrowright}$ & ○ & $\stackrel{\infty}{-}$ & $\bar{b}$ & $\bar{b}$ & $\underset{\infty}{\infty}$ & $\simeq$ & $\stackrel{\Upsilon}{\beth}$ \\
\hline
\end{tabular}

\subsection{Test Methods and Procedures}

Immediately after the completion of mixing, the freshly SCC mixes were tested to determine the filling ability, passing ability and segregation resistance.

The different hardened concrete compositions were submitted to the following tests: compressive, indirect splitting strengths, abrasion resistance test, cantabro test and rapid chloride permeability test to evaluate durability.

\subsubsection{Filling Ability Tests}

The filling ability is defined as the ability of SCC to flow in unconfined condition and fill every corner of the formwork under self-weight. The filling ability was measured with respect to slump flow, (T50 slump flow time, and V-funnel flow time). The slump flow was determined according to the test method given in ASTM C 1611/C 1611M [27].

The T50 slump flow time and V-funnel flow time (TV) was determined according to the test method given in EFNARC guidelines and specifications [28]. In T50 test, the time that a concrete sample requires for a spread of 50 $\mathrm{cm}$ diameter and for $\mathrm{V}$-funnel test, the time that a concrete sample needs for flowing out of a V-shaped box is determined to measure the filling ability of SCC.

\subsubsection{Passing Ability Tests}

The passing ability is the ability of SCC to flow in confined condition and completely fill all spaces within the formwork under self-weight and with no vibration. The passing ability was determined with respect to L-box flow (LB) and U-box flow (UB) following the test method depicted in EFNARC specifications and guidelines [28].

\subsubsection{Segregation Test}

The Japanese sieve stability and column segregation tests were carried out to determine the segregation resistance of SCC mixes. The Japanese sieve stability test was conducted. In this test, the mortar mass passing through a sieve size $(5 \mathrm{~mm})$ was expressed as the percentage of the total mortar content of original concrete sample to quantify the segregation resistance of SCC with respect to segregation ratio (SR).

\section{RESULTS AND DISCUSSION}

The test results for filling ability (slump flow, T50 slump flow time and V-funnel flow time), passing ability ( L-box flow and U-box flow), and segregation resistance of various SCC mixes are given in Table 3. 
Table 3: Properties of fresh SCC mixes.

\begin{tabular}{|c|c|c|c|c|c|c|}
\hline \multirow{2}{*}{ 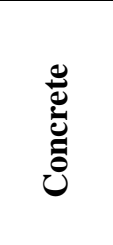 } & \multicolumn{3}{|c|}{ Filling ability } & \multicolumn{2}{|c|}{$\begin{array}{c}\text { Passing } \\
\text { ability }\end{array}$} & \multirow{2}{*}{ 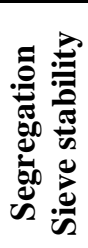 } \\
\hline & 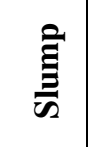 & 트 & 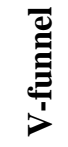 & $\frac{a}{8}$ & $\frac{\check{0}}{\frac{8}{b}}$ & \\
\hline 空 & 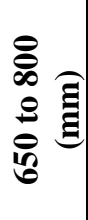 & 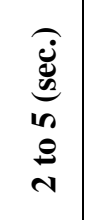 & 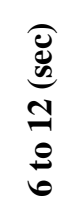 & 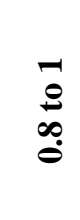 & 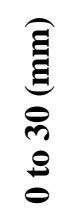 & $\underbrace{\overbrace{0}^{2}}_{\frac{1}{10}}$ \\
\hline $\begin{array}{l}\text { 0\% } \\
\text { MP }\end{array}$ & 630 & 3.2 & 11 & 0.82 & 31 & 6.3 \\
\hline $\begin{array}{c}10 \% \\
\text { MP }\end{array}$ & 660 & 2.8 & 9.4 & 0.85 & 25 & 8.7 \\
\hline $\begin{array}{c}20 \% \\
\text { MP }\end{array}$ & 680 & 2.6 & 8.5 & 0.88 & 22 & 10.5 \\
\hline $\begin{array}{c}30 \% \\
\text { MP }\end{array}$ & 700 & 2.4 & 8.1 & 0.9 & 20 & 11.3 \\
\hline $\begin{array}{c}40 \% \\
\text { MP }\end{array}$ & 720 & 2.2 & 6.9 & 0.94 & 15 & 12.8 \\
\hline
\end{tabular}

\subsection{Filling Ability}

\subsubsection{Slump Flow}

The slump flow results achieved for the concrete mixes with different MP percentages are given in Table 3 . The slump flow varied in the range of $630-720 \mathrm{~mm}$. According to EFNARC specifications and guidelines [28], the slump flow of SCC generally from 650 to $800 \mathrm{~mm}$. All mixes gives the requirement for slump flow except mix without MP.

The effect of MP on the slump flow of SCC is evident from Figure 3, which shows that as MP percentages increased the slump flow increased.

Increased in MP gives more workability to SCC, more free water were available to improve filling ability of concrete in addition the paste volume per unit aggregate content become higher, thus reducing the friction between aggregate particles. As the result, the dispersion of aggregate increased leading to a greater slump flow, but in mixes without MP the roughness of RCA and the low percentages of MP led to high friction between coarse aggregate so it give low slump.

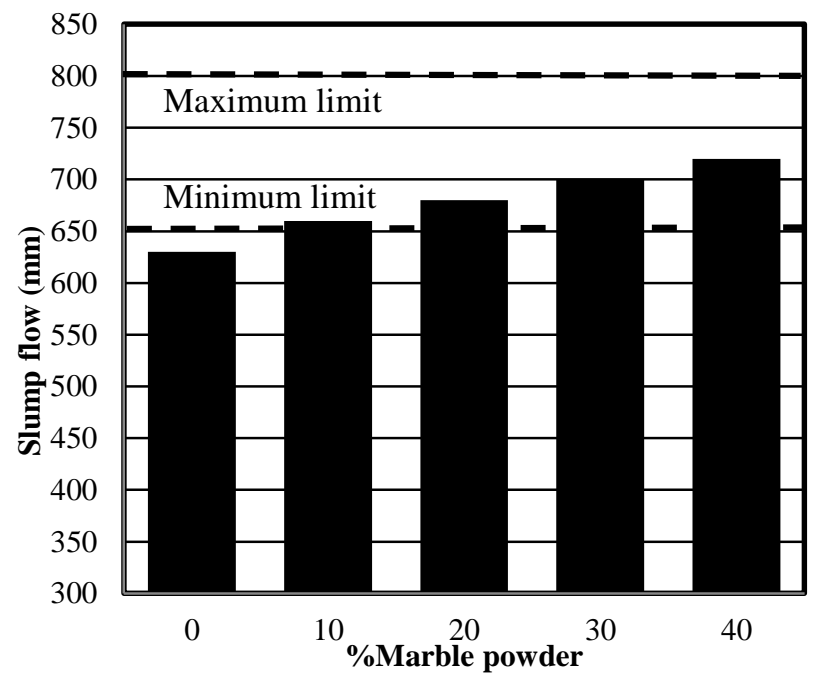

Figure 3: Effect of MP on slump flow of concrete.

\subsubsection{T50 Slump Flow Time}

The T50 slump flow time results of concrete with different MP percentages are given in Table 3. The T50 slump flow time varied in the range of $2.2-3.2 \mathrm{sec}$. According to EFNARC specifications and guidelines [28], the T50 slump flow time of SCC generally from 2 to $5 \mathrm{sec}$. Hence the T50 slump flow time was within the acceptable range.

The effect of MP on T50 slump flow time of SCC is evident from Figure 4.

As the MP percentages increased the T50 slump flow time decreased.

The MP fill the void between coarse aggregate so it reduce the surface roughness it led to reduction in friction between coarse aggregate so it reduce T50 slump flow time.

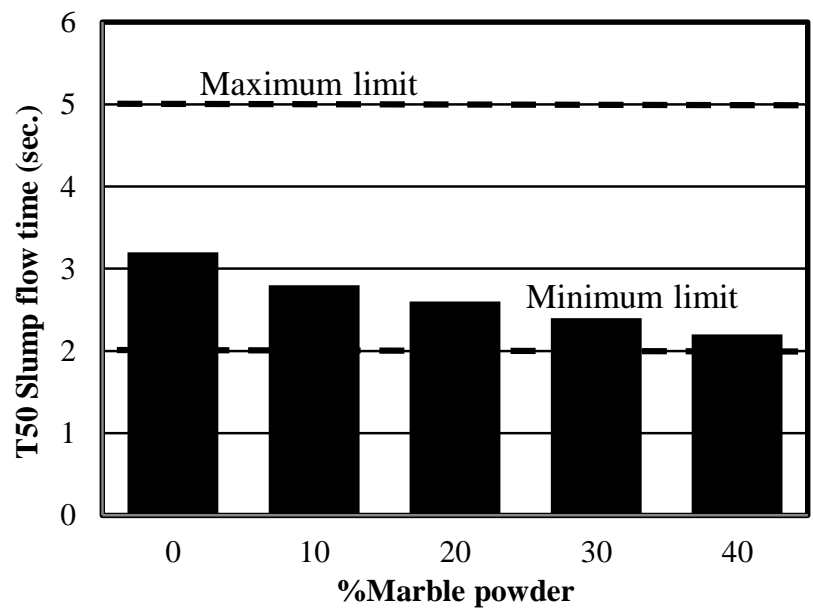

Figure 4: Effect of MP on T50 slump flow time. 


\subsubsection{V-funnel Flow Time}

The V-funnel flow time results of SCC mixes with various MP percentages are given in Table 3. The $\mathrm{V}$-funnel flow time varied in range $6.9-11$ sec. According to EFNARC specifications and guidelines [23], the V-funnel slump flow time of SCC generally from 6 to $12 \mathrm{sec}$. Therefore, the $\mathrm{V}$-funnel flow times were within the acceptable limits.

The high V-funnel flow time was mostly due to its low following ability, as perceived from the results of slump flow test. The variation in $\mathrm{V}$-funnel flow time followed a similar trend as observed in the case of T50 slump flow time. The effect of MP on the V-funnel flow time of SCC is evident from figure 5.

As shown from Figure 5 as the MP percentages increased the V-funnel flow time decreased. The reasons are the same as discussed in the case of T50 slump flow time (section 3.1.2). The shorter flow time indicates the greater flowing ability of concrete [28].

However, a very small flow time does not necessarily give an indication of good flowing ability. In fact, the SCC mixes with a very low $\mathrm{V}$-funnel flow time show excessive bleeding and/or segregation, thus causing blockage leading to intermittent concrete flow.

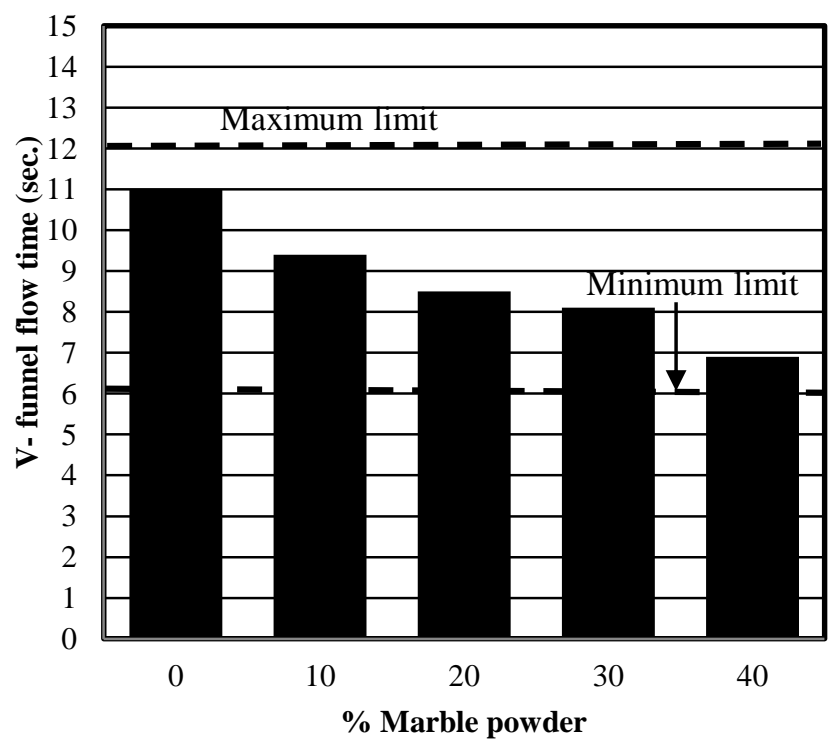

Figure 5: Effect of MP on V-funnel flow time.

\subsection{Passing Ability}

\subsubsection{L-box Flow}

The L-box flow results achieved for the concrete mixes with different MP percentages are given in Table 3. The ratio of heights at the beginning and end of flow varied in the range of $0.82-0.94$. According to EFNARC specifications and guidelines [28], the ratio of heights of L-box flow of SCC generally from 0.8 to 1 . All mixes give the requirement for L-box flow.
The effect of MP on the L-box flow of SCC is evident from Figure 6 , which shows that the L-box flow increased as MP percentages increased. In contrast, the L-box flow decreased for $0 \%$ and $10 \% \mathrm{MP}$ indicating a lower passing ability . Increased in MP gives more workability to SCC, more free water were available to improve filling ability of concrete in addition the paste volume per unit aggregate content become higher and reducing the friction between aggregate particles.

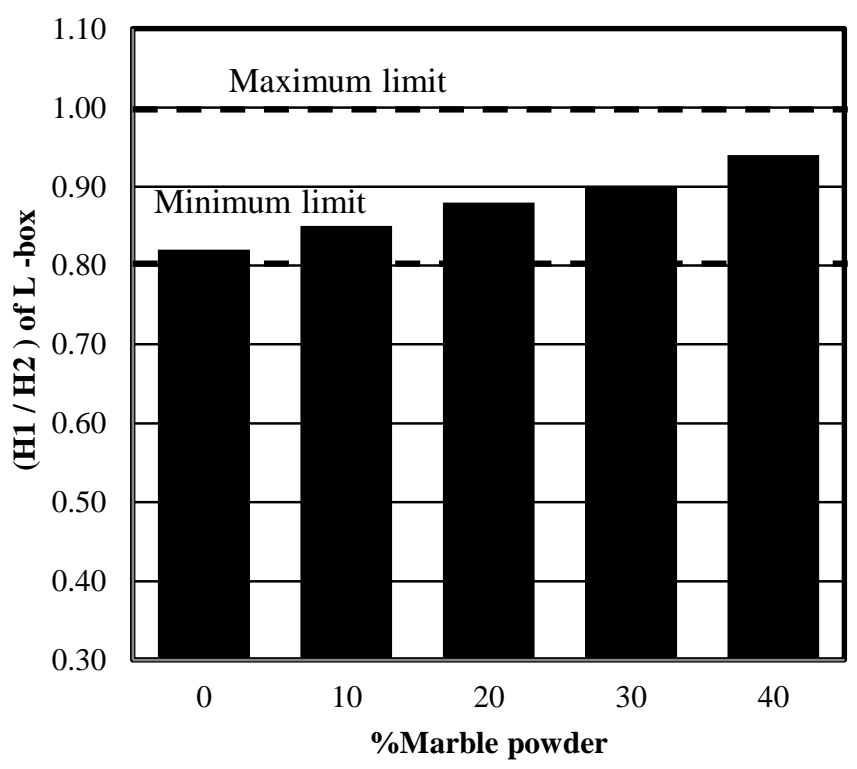

Figure 6: Effect of MP on L-box flow.

\subsubsection{U-box Flow}

The U-box flow results achieved for the concrete mixes with different MP percentages are given in Table 3. The difference in heights at the beginning and end of flow varied in the range of $15-31 \mathrm{~mm}$. According to EFNARC specifications and guidelines [28], the difference in heights of U-box flow of SCC generally from 0 to $30 \mathrm{~mm}$. All mixes gives the requirement for U-box flow except mixes without MP.

The effect of RCA on the U-box flow of SCC is evident from Figure 7, which shows that the U-box flow decreased as MP percentages increased. In contrast, the U-box flow increased at 0\% MP indicating a lower passing ability. Increased in MP gives more workability to SCC, more free water were available to improve filling ability of concrete in addition the paste volume per unit aggregate content become higher, thus reducing the friction between aggregate particles 


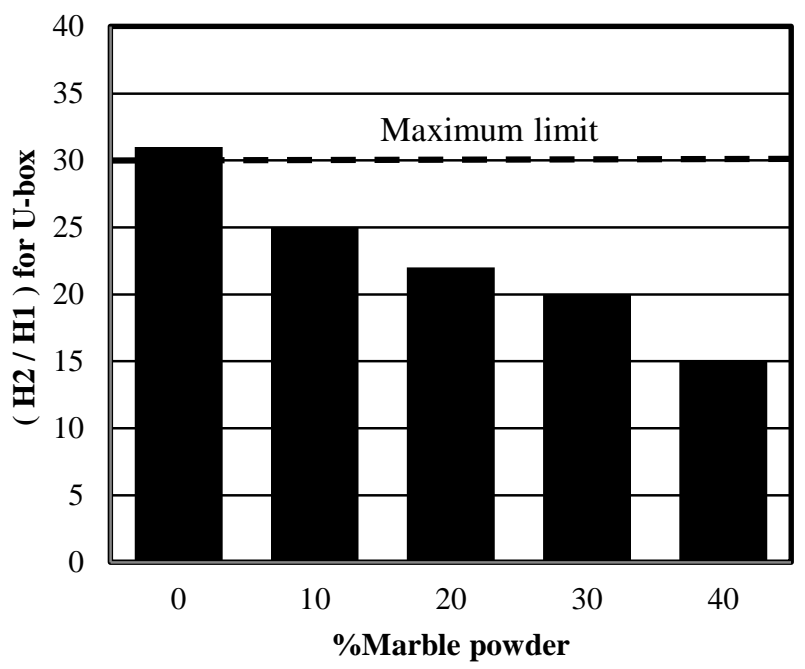

Figure 7: Effect of MP on U-box flow.

\subsection{Segregation Resistance}

\subsubsection{Segregation Ratio}

The segregation ratios of various SCC mixes are given in Table 3. The segregation ratio varied in the range of 6.3$12.8 \%$. According to EFNARC specifications and guidelines [28], the segregation ratio of SCC generally from 5 to $15 \%$. Thus, All mixes gives acceptable segregation resistance.

The effect of MP percentages on the segregation ratio is apparent from Figure 8. As MP percentages increased the segregation ratio increased.

The increasing in MP produce less cohesive concrete mix gives a higher slump flow but a lower flow time.

A decrease in the cohesiveness increases the separation of mortar, thus resulting in a higher value of segregation ratio.

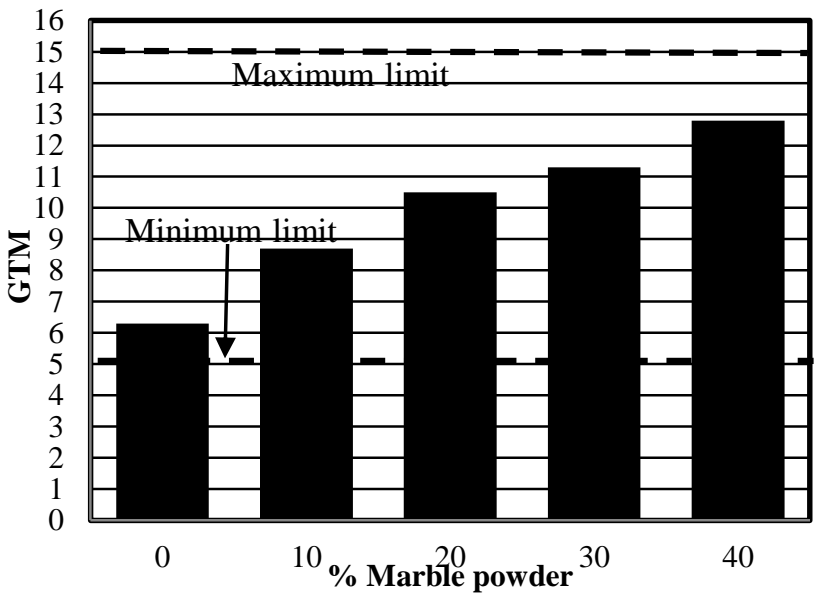

Figure 8: Effect of RCA on GTM

\subsection{Correlation Between V-funnel Flow Time and T50 Slump Flow Time}

The relationship between T50 slump flow time and Vfunnel flow time results is shown in Figure 9. It is obvious that the V-funnel flow time and T50 slump flow time of the SCC mixes were strongly correlated with a linear relationship. The correlation coefficient was 0.9886 , which suggests a strong relationship. The strong correlation was noticed because both T50 slump flow time and V-funnel flow time varied with the RCA content in a similar way.

Such strong correlation implies that either T50 slump flow or V-funnel flow test is adequate to assess the relative viscosity and cohesiveness of SCC.

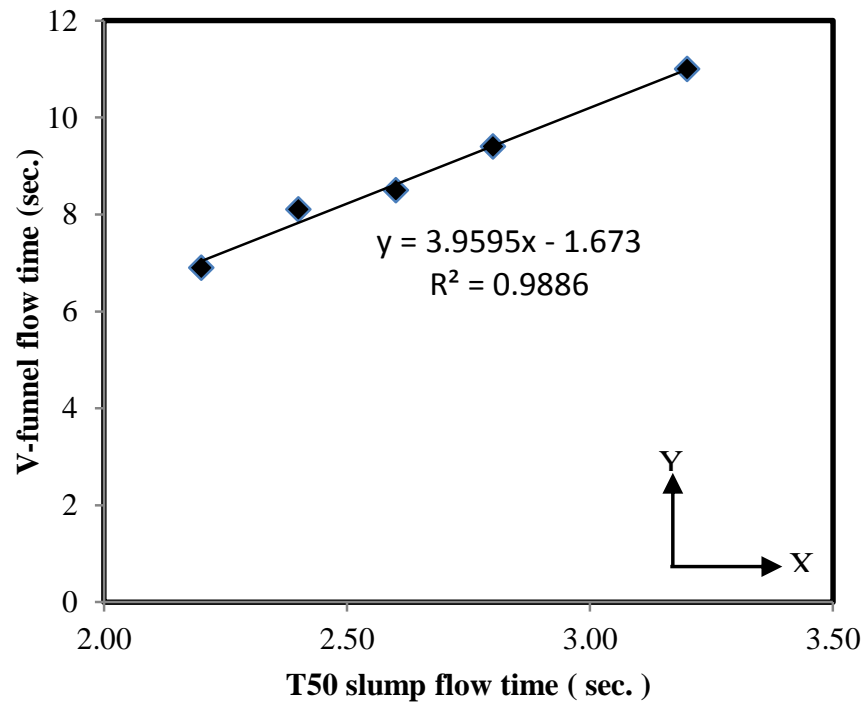

Figure 9: Correlation between V-funnel flow time and T50 slump flow time.

\subsection{Segregation Ratio vs. Slump Flow}

The relationship between slump flow and segregation ratio is shown in Figure 10. It is clear that the segregation ratio and slump flow of the SCC mixes were strongly correlated with a linear relationship. The correlation coefficient was 0.9887, which indicates a strong relationship. The strong correlation was obtained since both slump flow and segregation ratio varied identically with the content. Such strong correlation also suggests that slump flow can give an indication for the segregation resistance of SCC. 


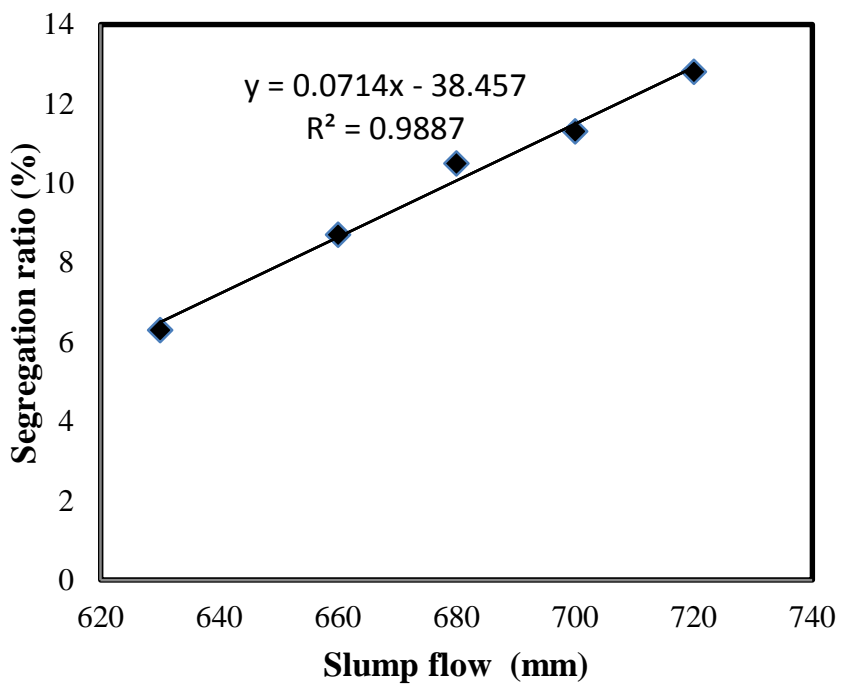

Figure 10: Correlation between segregation ratio and slump flow time.

\subsection{Hardened Concrete}

\subsubsection{Cube and Splitting Strength}

The test results for cube and splitting strength of various SCC mixes at age of 28 days are given in Table 4.

Table 4: Cube and splitting strength of various SCC mixes at age of 28 days.

\begin{tabular}{|c|c|c|}
\hline Concrete & $\begin{array}{c}\text { Cube strength } \\
\left(\mathrm{kg} / \mathrm{cm}^{2}\right)\end{array}$ & $\begin{array}{l}\text { Splitting strength } \\
\left(\mathrm{kg} / \mathrm{cm}^{2}\right)\end{array}$ \\
\hline 0\% MP & 326 & 25 \\
\hline $10 \% \quad M P$ & 416 & 29 \\
\hline $20 \% \quad M P$ & 253 & 20 \\
\hline $30 \% \quad$ MP & 246 & 19 \\
\hline $40 \% \quad \mathrm{MP}$ & 219 & 16 \\
\hline
\end{tabular}

The effect of MP on relative cube and splitting strength of SCC is evident from Figure 11, which shows that the cube and splitting strength decrease as MP percentages increase except at $10 \% \mathrm{MP}$ the cube and splitting strength increased.

The percentages of decreasing of cube strength reached to 22,24 and 33 for MP percentages $20 \%, 30 \%$ and $40 \%$ respectively, and for splitting strength the decreasing reached to 21,24 and 37 for MP percentages 20\%, 30\% and $40 \%$ respectively, but at $10 \%$ MP the percentages increased. Mixes with $30 \%$ and $40 \%$ MP give strength less than normal strength of concrete.

Increase in MP percentages reduce the cement content and reduce the bond between particles it lead to reduction in strength. Using 10\% MP fill the voids between particles and improve strength.
There is an inverse relationship between the compressive strength and MP percent . As the MP percentages increased, the compressive strength was reduced.

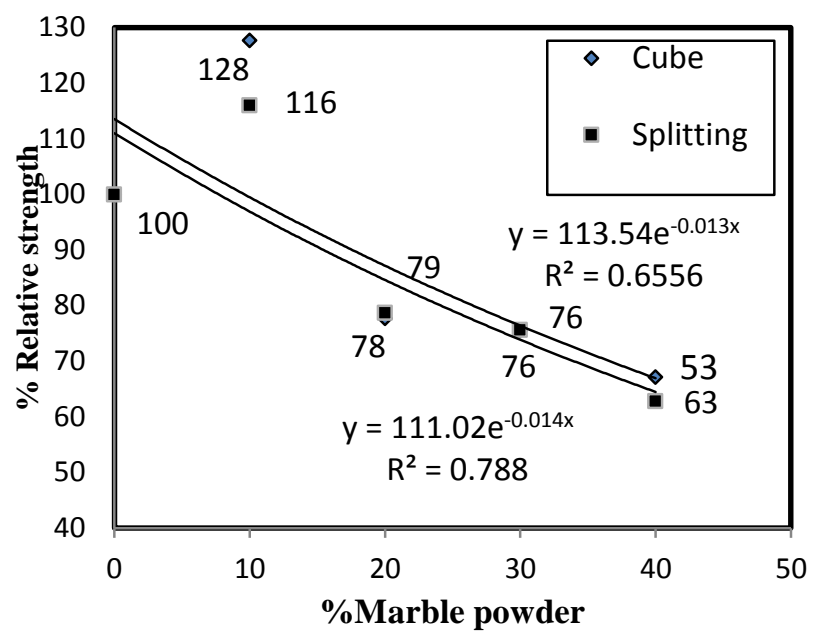

Figure 11: Effect of MP on cube and splitting strength of hardened concrete.

\subsubsection{Abrasion Resistance Test}

Test loss in thickness by abrasion for of various SCC mixes are given in Table 5 .

Table 5: Results of abrasion resistance test (loss in thickness) of various SCC mixes.

\begin{tabular}{|c|c|c|c|c|c|}
\hline Concrete & $\begin{array}{c}\text { W (gm.) } \\
\text { before }\end{array}$ & $\begin{array}{c}\mathbf{W}(\mathbf{g m} .) \\
\text { after }\end{array}$ & $\begin{array}{c}\Delta \mathbf{m} \\
(\mathbf{g m} .)\end{array}$ & $\begin{array}{c}\Delta \mathbf{t} \\
(\mathbf{m m})\end{array}$ \\
\hline $\mathbf{0 \%}$ & $\mathbf{M P}$ & 833 & 798 & 35 & 2.94 \\
\hline $\mathbf{1 0 \%}$ & $\mathbf{M P}$ & 819 & 785 & 34 & 2.91 \\
\hline $\mathbf{2 0 \%}$ & $\mathbf{M P}$ & 841 & 803 & 38 & 3.16 \\
\hline $\mathbf{3 0 \%}$ & $\mathbf{M P}$ & 815 & 776 & 39 & 3.35 \\
\hline $\mathbf{4 0 \%}$ & $\mathbf{M P}$ & 805 & 764 & 41 & 3.57 \\
\hline
\end{tabular}

The effect of MP on loss in thickness of SCC is evident from Figure 12, which shows that the loss in thickness increase as MP percentages increase except at 10\% MP the loss in thickness decrease. The decrease of loss in thickness at 10\% MP may be explained by possible binding activity caused by MP, which fill the voids and confer an abrasion resistance. Increasing MP over $10 \%$ reduce cement content, which make the pond between particles weak so loss in thickness increases. 


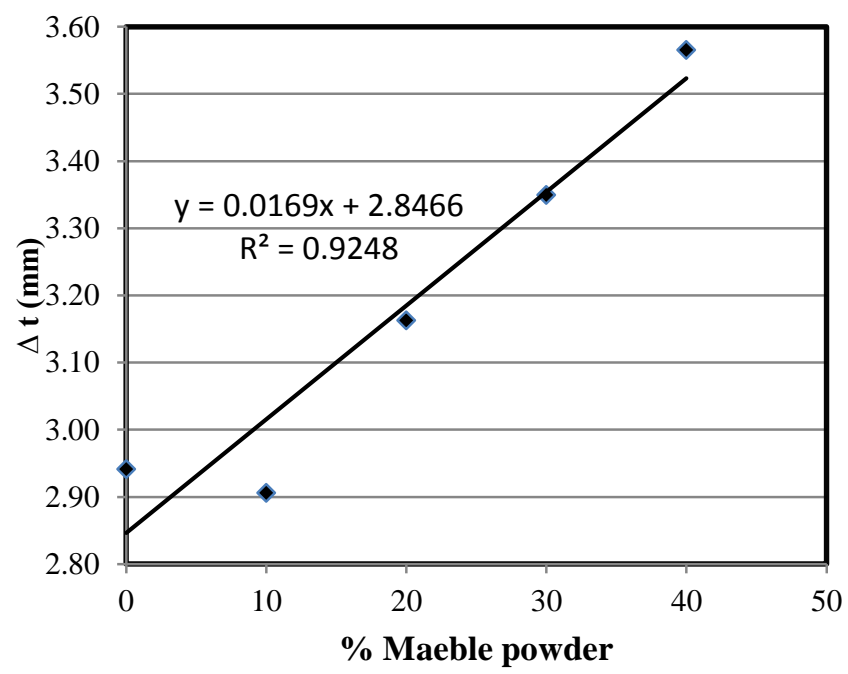

Figure 12: Effect of MP on loss of thickness by abrasion of hardened concrete.

\subsubsection{Cantabro Test}

Test loss in weight for of various SCC mixes are given in Table 6.

Table 6: Results of cantabro test (percentages of loss in weight) of various SCC mixes.

\begin{tabular}{|c|c|c|c|c|}
\hline \multicolumn{2}{|c|}{ Concrete } & $\begin{array}{c}\text { W (gm.) } \\
\text { before }\end{array}$ & $\begin{array}{c}\text { W (gm.) } \\
\text { after }\end{array}$ & C.T(\%) \\
\hline $\mathbf{0 \%}$ & MP & 4804 & 4425 & 7.9 \\
\hline $\mathbf{1 0 \%}$ & MP & 4792 & 4418 & 7.8 \\
\hline $\mathbf{2 0 \%}$ & MP & 4848 & 4450 & 8.2 \\
\hline $\mathbf{3 0 \%}$ & MP & 4748 & 4300 & 9.4 \\
\hline $\mathbf{4 0 \%}$ & MP & 4728 & 4270 & 9.7 \\
\hline
\end{tabular}

The effect of MP on percentages of loss in weight of SCC is evident from Figure 13, which shows that the percentages of loss in weight increase as MP percentages increase except at $10 \%$ MP the percentages decrease.

Loss in weight increase as MP increases because the weak connection between MP and cement baste. At $10 \% \mathrm{MP}$ the percentages decrease because MP work as filling material and fill the voids, which confer an abrasion resistance.

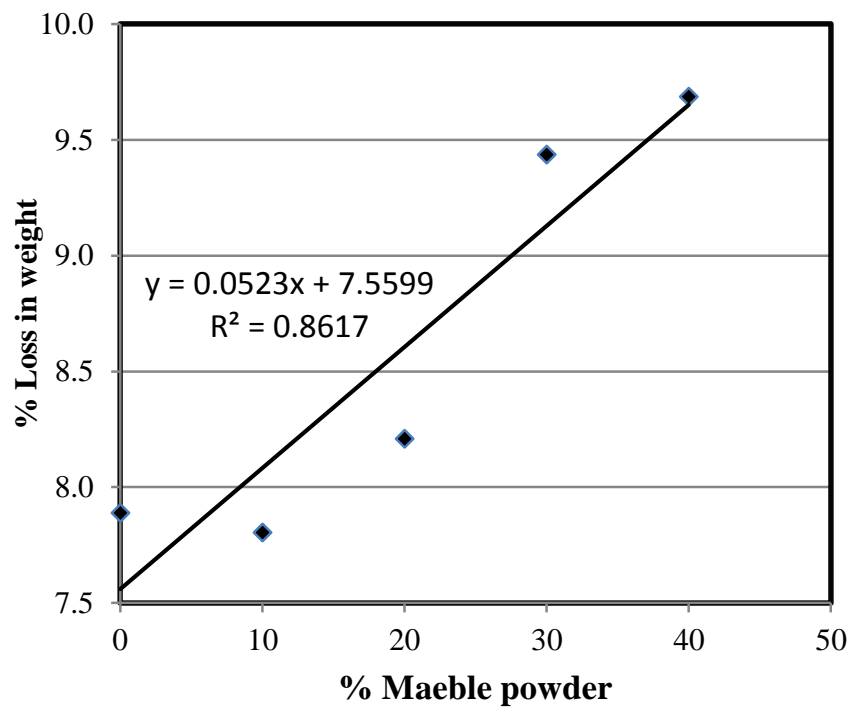

Figure 13: Effect of MP on percentages of loss in weight of hardened concrete.

\subsubsection{Rapid Chloride Permeability Test.}

Rating of chloride permeability for various SCC mixes is given in Table 7.

Table 7: Results of rating chloride permeability of various SCC mixes.

\begin{tabular}{|cc|c|c|}
\hline Concrete & $\begin{array}{c}\text { Charge } \\
\text { Coulombs }\end{array}$ & $\begin{array}{c}\text { Chloride } \\
\text { permeability }\end{array}$ \\
\hline $\mathbf{0 \%}$ & MP & 115 & Very Low \\
\hline $\mathbf{1 0 \%}$ & MP & 99 & Negligible \\
\hline $\mathbf{2 0 \%}$ & MP & 102 & Very Low \\
\hline $\mathbf{3 0 \%}$ & MP & 103 & Very Low \\
\hline $\mathbf{4 0 \%}$ & MP & 108 & Very Low \\
\hline
\end{tabular}

The effect of MP on rating chloride permeability of SCC mixes is evident from Figure 14 , which shows the charge(Coulombs) decrease at $10 \% \mathrm{MP}$ compared with control one, after increasing MP percentages over $10 \%$ the charge (coulombs) increased compared by mix containing $10 \% \mathrm{MP}$.

Permeability of concrete depends on pore of concrete. Pore of concrete decreased as MP percentages increase because MP fill the voids between particles, however increasing MP over 10\% as replacement of cement reduce the pond between particles and lead to week mix . 
The charge value 99 to 115 Coulombs is typically specified which is characterized as very low chloride permeability.

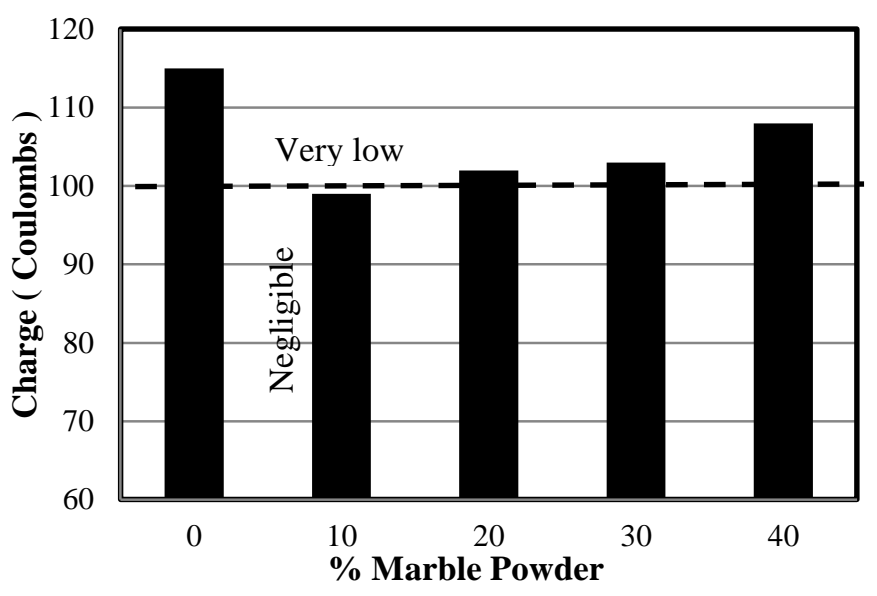

Figure 14: Effect of MP on rating of chloride permeability of hardened concrete.

\section{CONCLUSIONS}

The following conclusions can be drawn from the present study as follows:

The filling ability of SCC was improved at $10 \%, 20 \%$, $30 \%$ and $40 \%$ MP mainly due to MP reduce the friction between particles. The filling ability was reduced for mix without MP due to high friction between particles. The passing ability was satisfactory for all SCC mixes except mixes without MP. All SCC mixes had good segregation resistance, as noticed from the results of the Japanese sieve stability test. The segregation indices of concretes obtained from this test were significantly below the maximum limit $(15 \%)$.

All mixes contain $0 \%$ and $10 \% \mathrm{MP}$ give strength greater than that of normal concrete strength with various RCA percentages. Mixes with 10\% MP increase strength by about $28 \%$. The compressive and splitting tensile strength are decreased by about $26 \%$ by increasing marble powder percentages over $10 \%$.

The loss in thickness and volume increase by increasing MP except for $10 \%$ MP the losses decreased by $1 \%$, it may be due possible binding activity caused by MP which fill the voids and confer an abrasion resistance. Increasing MP over $10 \%$ reduce cement content which make the pond between particles weak so loss in thickness increase. Resistance to chloride penetration increased after using $10 \% \mathrm{MP}$.

\section{REFRANCES}

[1] H. Okamura, M. Ouchi, Self-compacting concrete. Development, present use and future, in: Proceedings of first international RILEM symposium on selfcompacting concrete, RILEM Publications, S.A.R.L., Stockholm,( 1999), 3-14.

[2] P.J.M. Bartos, M. Grauers, Self-compacting concrete, Concrete 33 (4), (1999), 9-13.

[3] D.W.S. Ho, A.M.M. Sheinn, C.C. Ng, C.T. Tam, The use of quarry dust for SCC applications, Cement and Concrete Research. 32, (2002), 505-511.

[4] Wenzhong Zhu, J.C. Gibbs, Use of different limestone and chalk powders in self-compacting concrete, Cement and Concrete Research. 35, (2005), 14571462.

[5] M. Ouchi, S. Nakamura, T. Osterson, S. Hellberg, M. Lwin, Applications of self -compacting concrete in Japan, ISHPC, Europe and the United States, (2003), $1-20$.

[6] Domingo Cabo A., Lazaro C., Lopez Gayarre F., Serrano Lopez MA.: Creep and shrinkage of recycled aggregate concrete, Construction and Building Material, (23), (2009), 2545-2553

[7] Cui ZL., Yang CH., Ohaga Y.: Durability test investigation on the recycled aggregate concrete, Science and Technology Engineer, 6( 21),( 2007), 3516-3519.

[8] Crentsil Sagoe KK., Broun T., Taylor AH.,: Performance of concrete made with commercially produced coarse recycled aggregate concrete, Cement and Concrete Research, 31( 9), (2010), 707712 .

[9] Otsuki N., Miyazato S., Yodsudjai W.: Influence of recycled aggregate on interfacial transition zone ,strength, chloride penetration and carbonation of concrete, Journal Material Civil Engineer, 15(5), (2013), 443-451.

[10] Alyamac Kurs_at Esat, Ince Ragip, A preliminary concrete mix design for SCC with marble powders, Construction Building Materials. 23, (2009), 12011210.

[11] Valeria Corinaldesi, Giacomo Moriconi, Tarun R. Naik, Characterization of marble powder for its use in mortar and concrete, Construction Building Materials. 24, (2010), 113-117. 
[12] A. Yahia, M. Tanimura, Y. Shimoyama, Rheological properties of highly flowable mortar containing limestone filler-effect of powder content and W/C ratio Cement and Concrete Research. 35, (2005), 532- 539 .

[13] M. Sahmaran, H.A. Christianto, I.O. Yaman, The effect of chemical admixtures and mineral additives on the properties of self-compacting mortars, Cement and Concrete Research. 28 (5), (2016), 432-440.

[14] Mucteba Uysal, Kemalettin Yilmaz, Metin Ipek, The effect of mineral admixtures on mechanical properties, chloride ion permeability and permeability of self-compacting concrete, Construction Building Materials. 27 ,(2012), 263-270.

[15] M. Sonebi, L. Svermova, P.J.M. Bartos, Factorial design of cement slurries containing limestone powder for self-consolidating slurry-infiltrated fiber concrete, ACI Mater. J. 101 (2), (2014), 136-145.

[16] Mucteba Uysal, Kemalettin Yilmaz, Effect of mineral admixtures on properties of self-compacting concrete, Cement and Concrete Research. 33, (2011), 771-776.

[17] G. Ye, X. Liu, G. De Schutter, A.-M. Poppe, L. Taerwe, Influence of limestone powder used as filler in SCC on hydration and microstructure of cement pastes, Cement and Concrete Research. 29 (2), (2007), 94-102.

[18] A.M. Poppe, G.D. Schutter, Cement hydration in the presence of high filler contents, Cement and Concrete Research. 35 (12), (2005), 2290-2299.

[19] A.S.E. Belaidi, L. Azzouz, E. Kadri, S. Kenai, Effect of natural pozzolana and marble powder on the properties of self-compacting concrete, Construction Building Materials. 31, (2012), 251-257.

[20] B. Felekog lu, K. Tosun, B. Baradan, A. Altun, B. Uyulgan, The effect of fly ash and limestone fillers on the viscosity and compressive strength of selfcompacting repair mortars, Construction Building Materials. 36 (9), (2006), 1719-1726.

[21] Ilker Bekir Topcu, Turhan Bilir, Tayfun Uygunog` lu, Effect of waste marble dust content as filler on properties of self-compacting concrete, Construction Building Materials, 23, (2009), 1947- 1953.

[22] S. Assie, G. Escadeillas, V. Waller, Estimates of selfcompacting concrete 'potential' durability,
Construction Building Materials. 21 (10), (2007), 1909-1917.

[23] Siddique R. Bier, Effect of fine aggregate replacement with Class $\mathrm{F}$ fly ash on the mechanical properties of concrete, Cement and Concrete Research. 27(4), (2003), 539-47.

[24] Ann KY., Moon HY., Kim YB., Ryou J. Durability of recycled aggregate concrete using pozzolanic materials, Waste Manage. 28, (2008) ,993-999.

[25] Kou SC., Poon CS., Chan D., Influence of fly ash as a cement replacement on the properties of recycled aggregate concrete, ASCE Material and Civil Engineer. 19(9), (2007), 709-7017..

[26] Kou SC., Poon CS., Chan D., Influence of fly ash as a cement addition on the properties of recycled aggregate concrete, Materials and Structures. 41(7), (2008), 1191-1201.

[27] ASTM C 1611/C 1611M: Standard test method for slump flow of self-consolidating concrete, Annual Book of ASTM Standards, American Society for Testing and Materials, Philadelphia, USA, (2009).

[28] EFNARC: Specifications and guidelines for selfconsolidating concrete, European Federation of Suppliers of Specialist Construction Chemicals (EFNARC), Surrey, UK, (2002). 